\title{
Intracortical cartography in an agranular area
}

\author{
Gordon M. G. Shepherd* \\ Department of Physiology, Feinberg School of Medicine, Northwestern University, Chicago, IL, USA
}

A well-defined granular layer 4 is a defining cytoarchitectonic feature associated with sensory areas of mammalian cerebral cortex, and one with hodological significance: the local axons ascending from cells in thalamorecipient layer 4 and connecting to layer 2/3 pyramidal neurons form a major feedforward excitatory interlaminar projection. Conversely, agranular cortical areas, lacking a distinct layer 4 , pose a hodological conundrum: without a laminar basis for the canonical layer $4 \rightarrow 2 / 3$ pathway, what is the basic circuit organization? This review highlights current challenges and prospects for local-circuit electroanatomy and electrophysiology in agranular cortex, focusing on the mouse. Different lines of evidence, drawn primarily from studies of motor areas in frontal cortex in rodents, support the view that synaptic circuits in agranular cortex are organized around prominent descending excitatory layer $2 / 3 \rightarrow 5$ pathways targeting multiple classes of projection neurons.

Keywords: motor, frontal, synaptic circuits, pyramidal neuron

Edited by:

Edward M. Callaway,

The Salk Institute, USA

Reviewed by:

Takeshi Kaneko, Kyoto University, Japan Gilad Silberberg, Karolinska Institute,

Sweden

* Correspondence:

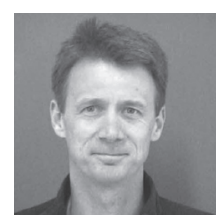

Gordon M. G. Shepherd is an Assistant Professor in the Department of Physiology, Northwestern University Medical School. He trained at Harvard (M.D., Ph.D.), Massachusetts General Hospital (Neurology), University of Oslo (Post-doctoral Fellow), and Cold Spring Harbor Laboratory (Post-doctoral Fellow). His research focuses on cortical circuits in motor-frontal areas of rodents, using optical/electrophysiological tools to study synaptic circuit organization in normal cortex and model systems for autism, Rett syndrome, epilepsy, and motor neuron disease. g-shepherd@northwestern.edu

\section{INTRODUCTION}

Studies of cortical circuit organization have largely focused on circuits in sensory areas, particularly visual and somatosensory cortex. Progress over decades has led to a detailed and sophisticated understanding of cortical circuit organization in sensory cortex, serving as a model for cortical circuits in general (Douglas and Martin, 2004; Thomson and Lamy, 2007) and inspiring largescale modeling of cortical circuit organization (Markram, 2006).

There are numerous advantages of sensory cortex for cortical circuit analysis. Receptive field properties can be studied in a low-dimensional manner. Feedforward excitatory pathways are evident, such as $\mathrm{V} 1 \rightarrow \mathrm{V} 2$ (primary to secondary areas in visual cortex). The inputs are close to the sensory periphery in terms of synaptic depth in the network. Cytoarchitectonic features in particular render sensory cortex amenable to analysis, as multiple layers and sub-layers are sharply demarcated, exemplified by the line of Gennari (layer 4B) and inner band of Baillarger (in L5) in primate primary visual cortex. In primates the total number of cytoarchitectonically sharp layers and sub-layers is at least 11. A prominent cytoarchitectonic feature of primary sensory cortex in many species and areas is a well-demarcated 'granular' layer 4 (L4), so named for the grainy appearance due to numerous small neurons with stellate or stellate-like morphology (e.g.'star pyramids') (see Staiger et al., 2004).

In contrast, in 'agranular' cortex - frontal areas lacking a well-defined granular layer (L4) cortical circuit analysis is hampered by several seeming disadvantages (Keller, 1993). The inputs seem less well defined because they arise from areas synaptically distant from peripheral sensory streams, and are not easily controllable in the way sensory inputs are. It is not straightforward to proceed 'forwards' or 'backwards' in agranular cortical circuits (Shipp, 2005).

Fortunately, there are also some advantages for cortical circuit analysis in agranular areas of motorfrontal cortex. Motor outputs can be evoked by stimulation or behaviorally, and can be monitored in a variety of ways. The subcortical organization of the motor system has been extensively character- 
Agranular cortex

Areas of the cerebral cortex lacking a distinct layer 4, typically related to a paucity or lack of stellate cells. In mice, essentially all cortical areas anterior and medial to the somatosensory (barrel) cortex are agranular. Frontal cortex is defined as areas $4,6,8,10$, and 11

(Caviness, 1975). ized. Moreover, the inputs arise from three main sources (as for sensory cortex): other cortical areas, thalamic nuclei, and ascending neuromodulatory projections. Still, the cytoarchitectonic boundaries are blurry, as motor-frontal areas lack the distinct stellate-rich L4 characteristic of sensory cortex. So, for circuit mapping endeavors, there are 'no stars to steer by. Interestingly, in primates and particularly in humans, the evolutionarily newer far-anterior frontal areas, rostral to primary motor areas, do possess a more distinct granular L4 (Wise, 2008). However, the absence of a distinct L4 throughout the phylogenetically older motor-frontal areas including all anterior areas of mouse neocortex means that circuit studies cannot be referenced to the trusty L4 cytoarchitectonic landmarks as they can be in sensory cortex. In our studies, we routinely reference the stimulation and recording sites to their normalized radial positions along the pia-to-white-matter axis (i.e., pia $=0$, white matter =1) (Weiler et al., 2008; Yu et al., 2008).

The absence of a distinct layer 4 has previously been noted to pose a conundrum for applying rules for feedforward/feedback hierarchical organization of inter-areal connectivity (Shipp, 2005) the rules were developed from studies of visual and somatosensory areas, but in some respects seem to break down in motor-frontal areas. In a similar fashion, agranularity poses a conundrum for deciphering the local, inter-laminar circuits in terms of the wiring diagrams for local circuits developed from studies of visual and somatosensory areas (Callaway, 1998; Douglas and Martin, 2004; Thomson and Lamy, 2007). Without a thalamorecipient, stellate-enriched, layer 4, what are the basic circuits?

\section{AREAS}

The remainder of this review focuses chiefly on mouse motor-frontal cortex. Caviness (1975), parcellating the mouse cortex by cytoarchitectonic features, delineated several frontal agranular areas including a main anteromedial area (area 6), a narrow intermediate zone (area 4 ) on the lateral aspect of the cortex between area 6 and granular somatosensory cortex (barrel cortex, area 3), and a medial strip along the interhemispheric fissure (area 8). Two additional small agranular areas (areas 10,11) are located lateral to area 6. The location of frontal agranular areas in the mouse largely resembles that described in rats (Wise and Donoghue, 1986; Brecht et al., 2004) and squirrels (Wong and Kaas, 2008). Primary motor (M1), secondary motor (M2), premotor, sensorimotor, frontal, frontal-association, and prefrontal cortex are terms variously used to describe different areas in different species. Here, for convenience, the term 'motor-frontal' is used as a general term to refer to agranular frontal areas, particularly cortical areas 4 and 6 of Caviness (Figure 1A). For further details the reader is referred to that study (Caviness, 1975).

A potential source of confusion is the location of the forelimb motor representation area in rodents, as this extends a bit from motor-frontal areas into somatosensory areas, partially overlapping with sensory representations (hence the term 'sensorimotor' cortex) (Wise and Donoghue, 1986; Li and Waters, 1991; Brecht et al., 2004; Ayling et al., 2009). This pattern largely matches the areal distribution of corticospinal neurons, which is densest in Caviness' area 4 and posterior area 6 (i.e., the posterior part of motor-frontal cortex) but straddles the boundary between primary motor (M1) and primary somatosensory (S1) cortex (i.e., between agranular and granular cortex) and extends slightly into forelimb zone of somatosensory cortex. Incomplete separation of $\mathrm{M} 1$ and S1, characteristic of rodents, has been described as grade 3 sensorimotor separation (grade 4, observed in primates, being the most complete separation) (Frost et al., 2000).

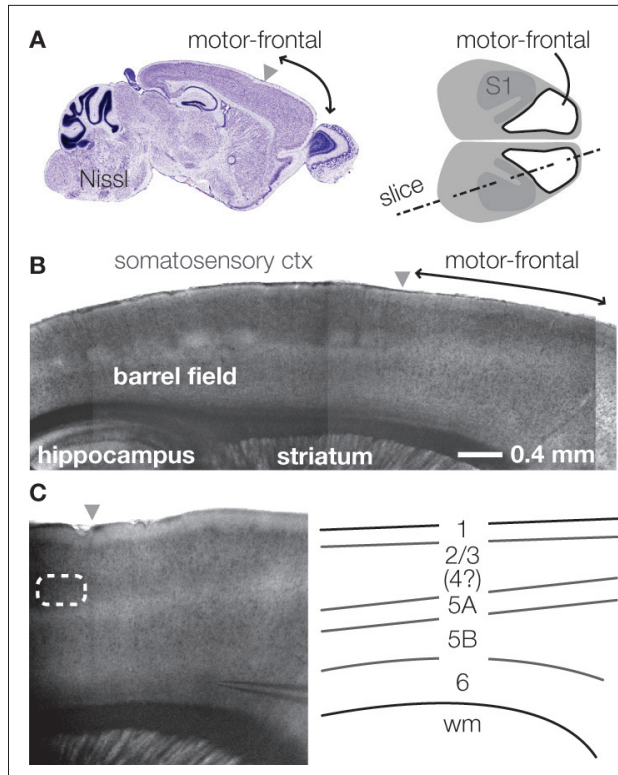

Figure 1 | Layers in the mouse's agranular cortex. (A) Sagittal section through the mouse's motor-frontal cortex (left). Source: Allen Brain Atlas' reference atlas (mouse.brain-map.org). Schematic top view of mouse cortex, showing location of motor-frontal area (right). (B) Bright-field image of slice (slice angle indicated in (A), right). Anterior is to the right. The agranular motor-frontal cortex lacks the distinct layer 4 barrels seen in somatosensory cortex. (C) Laminar labeling scheme in mouse motor-frontal cortex.

Bright-field image of motor-frontal cortex slice (left). Schematic (right) indicates the major layers. 


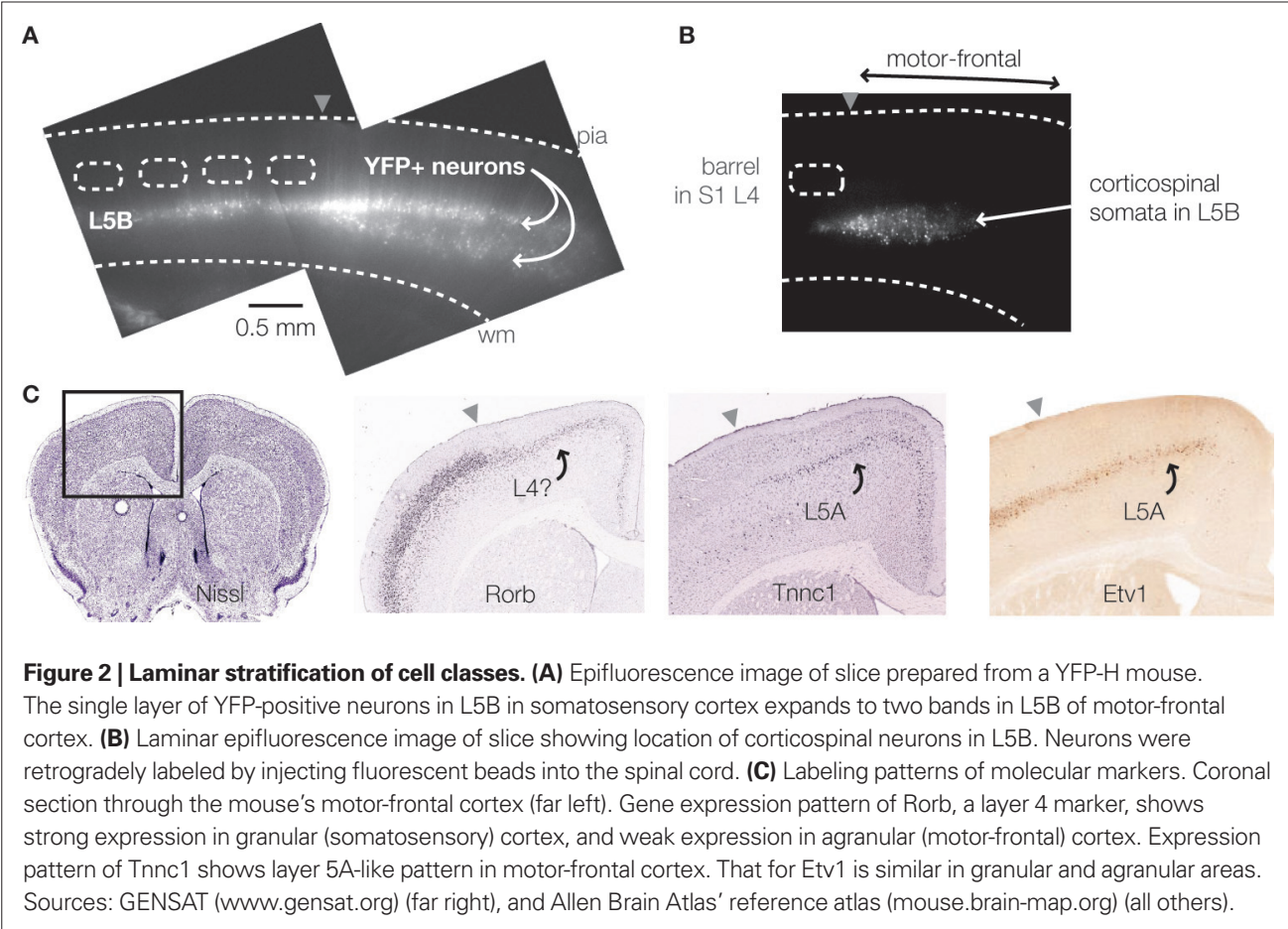

\section{LAYERS}

Slices of motor-frontal cortex show characteristic laminar banding patterns, with some boundaries sharper than others (Figure 1B). Slices cut to include both motor-frontal and adjacent somatosensory cortex invite extension of the laminar labeling scheme for S1 (about which there is general agreement) over to neighboring M1 - with the exception of L4, which is indistinct in the agranular area (Figure 1C). Thus, based on cytoarchitectonics, the basic layers of motor-frontal cortex include: L1, L2/3, L5A, L5B, and L6. The L5B/6 border is the blurriest. Compared to its appearance in S1, L5A in M1 is somewhat thicker and assumes a more superficial location in more anterior and medial regions; L5B accordingly appears thicker.

Indeed, in the mouse, agranular cortex is considerably thicker than more posterior areas (see Figure 1A). The difference is due to the greater fraction of neuropil (i.e., 'wiring'; axons and dendrites), as the total number of neurons under a square millimeter of cortex is roughly similar across the cortex in mice (Schuz and Palm, 1989). The agranular cortex at the far-frontal pole is $\sim 1.5 \mathrm{~mm}$ thick, compared to $\sim 0.7 \mathrm{~mm}$ at the posterior end (visual cortex; see Figure 1A). The lower density of neuronal somata in agranular cortex presumably contributes to the indistinctness of laminar borders.

In addition to the radial stratification of the cortex based on cytoarchitectonic appearance (a function of cell sizes and densities, among other factors), similar but also additional lamination patterns are apparent at the levels of defined cell classes and circuits. Genetically defined cell classes, such as layer 5 neurons expressing YFP under control of the thy-1 promoter in the YFP-H line of transgenic mice (Feng et al., 2000), can show remarkably sharp lamination. We observed an unusual laminar labeling pattern in L5B in motor-frontal cortex of these mice (Yu et al., 2008): unlike granular cortical areas, in agranular cortex there was a striking doublebanded distribution of these neurons, consistent with the apparent expansion of L5B in agranular cortex (Figure 2A). Projectionally defined cell classes (e.g. corticospinal, corticostriatal) also occupy distinct, stereotypic laminar distributions (Figure 2B). Gene expression patterns often show laminar differences (Figure 2C). A major challenge is to understand how gene expression patterns relate to the functional properties of neurons and circuits. Progress is being made towards elucidating the molecular specification of corticospinal neurons in particular (Molyneaux et al., 2007).

Although agranular cortex lacks a distinct $\mathrm{L} 4$, it receives abundant thalamic innervation. Thalamocortical axons from the ventrolateral (VL) complex, the main relay from the basal ganglia and deep cerebellar nuclei, are densest in L3 (Strick and Sterling, 1974; Jones, 1975; Wise and Donoghue, 1986). Recent work has clarified the differential distribution of the ventral anterior and VL afferent 

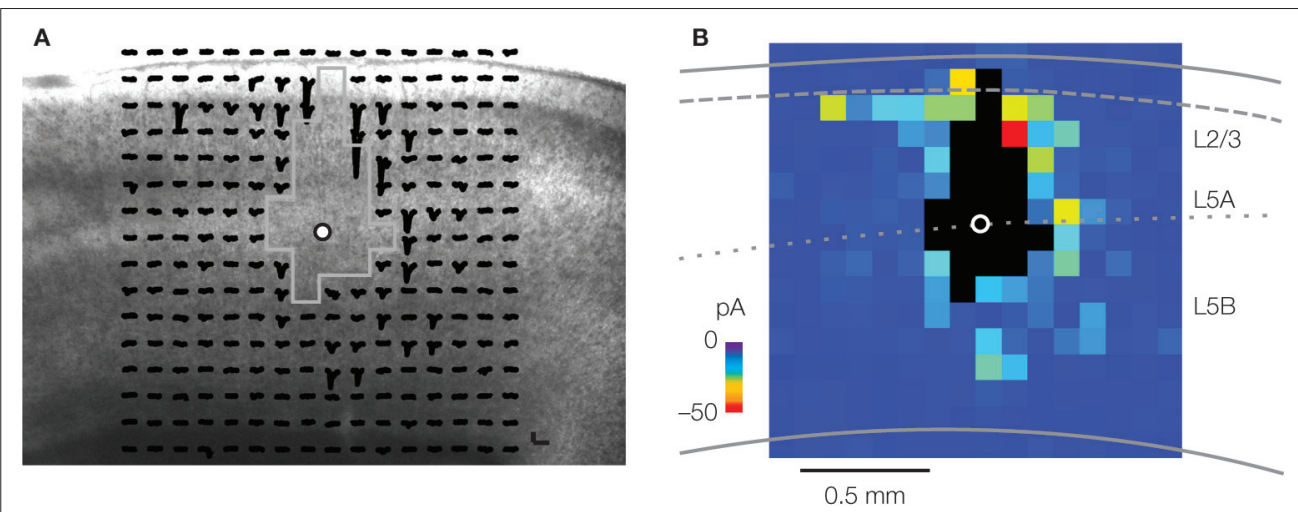

Figure 3 | Synaptic mapping of excitatory inputs to layer 5 pyramidal neurons. (A) Image of slice with array of traces superimposed, showing spatial distribution of presynaptic partners of a pyramidal neuron located at the border of L5A and L5B. Strongest responses were evoked at stimulating sites in L2/3 and L5. (B) Synaptic input map for the same neuron, constructed by averaging the responses to photostimulation across the three map trials. For details, see Yu et al. (2008)

system in the rat, with ganglionic-type axons going more to L1 and L5 and cerebellar-type axons to L3 (Kuramoto et al., 2009). Motor-frontal cortex is also innervated by other thalamic nuclei, including the medial division of the posterior nucleus (POm) and the centrolateral nucleus of the intralaminar complex, especially in L1 and upper L5 (Wise and Donoghue, 1986; Kichula and Huntley, 2008). The dense innervation of L3 in agranular cortex occurs at roughly the same cortical depth as the granular layer in sensory areas, suggesting homology. Consistent with this, 'L4 markers' like Rorb are expressed in agranular cortex, albeit weakly compared to sensory cortex (Figure 2C). Indeed, similar patterns are observed with immunocytochemical labeling of vesicular glutamate transporter 2 , although the granular/agranular difference is more pronounced in, for example, tree shrews compared to rodents (Kaneko and Fujiyama, 2002; Wong and Kaas, 2008, 2009). Circuit mapping studies (see below) provide additional functional evidence for a L4-like layer in motor-frontal cortex, in the form of ascending excitatory $\mathrm{L} 3 / 5 \mathrm{~A} \rightarrow \mathrm{L} 2 / 3$ pathways (Weiler et al., 2008) that resemble $\mathrm{L} 4 / 5 \mathrm{~A} \rightarrow 2 / 3$ pathways in sensory cortex.

\section{CIRCUITS}

Earlier studies of synaptic circuits in motorfrontal cortex (of rats in particular) focused especially on horizontal connections and plasticity mechanisms therein (Wise and Donoghue, 1986; Keller, 1993), an issue particularly germane to the question of how somatotopic representation is encoded at the level of synaptic circuits in the motor cortex (Schieber, 2001).

Examining vertically oriented local circuits, Kaneko and colleagues (Kaneko et al., 1994a,b, 2000; Cho et al., 2004) described L3 $\rightarrow$ corticospinal connections in motor cortex (rat and cat), based on responses in labeled corticospinal neurons evoked by extracellular stimulation directed at the lower portion of L2/3. In more recent work, the same group has begun to dissect the thalamocortical side of the local circuit, finding evidence for distinct roles for basal ganglionic and cerebellar influences on corticospinal outputs, in the context of the local excitatory network (Kuramoto et al., 2009).

Anatomical evidence for $\mathrm{L} 3 \rightarrow$ corticospinal connections in primates comes from recent studies using rabies virus for retrograde transsynaptic tracing (Rathelot and Strick, 2006, 2009). Following injection of virus into arm muscles, label eventually appeared in motor cortex, initially in layer 5 corticospinal neurons in a restricted area of primary motor cortex located caudally along the motor strip in the precentral gyrus. These were interpreted to be corticomotoneuronal (CM) neurons - corticospinal neurons (upper motor neurons) having direct contacts onto spinal motor neurons (lower motor neurons). Allowing more time for the virus to propagate further 'upstream' into the network revealed an interesting pattern. In addition to the CM neurons, they observed labeled cells in two places. One of these was layer 5 of rostrally adjacent primary motor cortex. They interpreted these as being corticospinal neurons having disynaptic contacts onto LMNs, via local-circuit interneurons in the spinal cord. Because evolutionarily the monosynaptic arrangement is considered a primate specialization for fine finger motility, and the disynaptic arrangement is probably common to all mammals (including most non-hand-related corticospinal connections in primates), the CM subregion of M1 is referred to as 'new M1' and the 
Laser scanning photostimulation (LSPS) by glutamate uncaging An electroanatomical circuit mapping tool based on the combination of laser uncaging of glutamate and scanning microscopy (Callaway and Katz, 1993).

Laminar connectivity matrix Representation of presynaptic $\rightarrow$ postsynaptic connections, in terms of the laminar locations of the pre- and postsynaptic neurons. Data from LSPS (Weiler et al., 2008), pair recording (Lefort et al., 2009), and anatomical (Binzegger et al., 2004; Stepanyants et al., 2008) studies have been used for laminar connectivity matrix analysis.

Sub-laminar local circuit organization

The idea that circuit topography does not exactly follow cytoarchitectonic topography, but can exhibit stratified structure within or across layers. An example is the sub-laminar structure evident in both L/3 and L5 in the synaptic input maps of YFP-positive and YFP-negative pyramidal neurons in mouse motor-frontal cortex (Yu et al., 2008). later-labeled adjacent rostral region as 'old M1'. The second place that labeled neurons appeared after letting the virus propagate further backwards into the network was in new $\mathrm{M} 1$, in the layers above L5 - i.e., in L2/3. This pattern was interpreted as revealing direct $\mathrm{L} 2 / 3 \rightarrow 5$ connections within the local circuit in M1.

Corticospinal neurons constitute a rather small fraction of the neurons in motor-frontal cortex (Keller, 1993), but the local circuits of the more numerous non-corticospinal pyramidal neurons have received much less attention. Recently, we used a synaptic mapping strategy based on glutamate uncaging and laser scanning photostimulation to map the local excitatory pathways in the forelimb area of mouse motor-frontal cortex (Weiler et al., 2008). Unlabeled pyramidal neurons in brain slices were recorded, one by one, located in all layers. For each neuron, hundreds of connections from across all layers were tested. The data set was analyzed to obtain a laminar presynaptic $\rightarrow$ postsynaptic connectivity matrix description of the excitatory network. The local network was dominated by $\mathrm{L} 2 / 3 \rightarrow 5$ pathways. For most $\mathrm{L} 5$ neurons receiving $\mathrm{L} 2 / 3$ inputs, the inputs arose from upper L2/3 (i.e., L2) (Figure 3), but for some the inputs were from both upper and lower L2/3, and a few cells showed mainly a lower L2/3 (i.e., L3) input patterns, suggesting that L2/3 does not project monolithically to lower layers but that upper and lower sub-layers within L2/3 can differentially project to L5 neurons. Horizontal projections were present, including intralaminar and oblique (horizontal and inter-laminar), but even at greater horizontal distances the $\mathrm{L} 2 / 3 \rightarrow 5$ pathways were stronger than $\mathrm{L} 2 / 3 \rightarrow 2 / 3$ or L5 $\rightarrow 5$ horizontal pathways. Other pathways in the local circuit (prominent but weaker compared to $\mathrm{L} 2 / 3 \rightarrow 5$ ) included an inter-laminar pathway, $\mathrm{L} 3 / 5 \mathrm{~A} \rightarrow 2 / 3$, topographically similar to, but weaker than, ascending $\mathrm{L} 4 \rightarrow 2 / 3$ and $\mathrm{L} 5 \mathrm{~A} \rightarrow 2 / 3$ pathways characteristic of sensory cortex (Wood et al., 2009).

In that study (Weiler et al., 2008), pyramidal neurons were 'identified' solely on the basis of their radial (laminar) soma positions. Indeed, one conclusion was that radial soma position is a major determinant of circuit topography, and therefore important in specifying a neocortical pyramidal neuron's 'identity'. An obvious next step is to examine L2/3 inputs to L5 neurons whose identities are additionally specified either by genetic or anatomical labeling techniques. One mouse line that has become popular for a variety of circuit-level studies is the YFP-H line, mentioned above (Feng et al., 2000). Several variants have also been developed that show similar laminar expression pat- terns in cortex, including the GFP-M line (Feng et al., 2000) and a channelrhodopsin-2 expressing line (Arenkiel et al., 2007).

We recently (Yu et al., 2008) used the YFP-H transgenic mouse line to explore the possibility of sub-pathways within the dominant pathway, $\mathrm{L} 2 / 3 \rightarrow 5$. As noted above, we found that the single-layer YFP expression pattern seen in granular cortex expanded into a double-layer pattern in agranular cortex, demonstrating the thickening of L5B in motor-frontal areas, and implying the existence of at least three L5B sub-layers in agranular cortex. Mapping inputs to cells in the upper or lower YFP-positive band, we found that upper-5B cells received inputs from lower $\mathrm{L} 2 / 3$, in contrast to the upper-L2/3 input pattern observed for unlabeled neighboring neurons. Neither labeled nor unlabeled lower-layer neurons received strong descending inputs. These results provide further evidence for the concept of sub-laminar local circuit organization. An intriguing aspect of the YFP-positive circuit 'phenotype' is that it appears more consistent (than the YFP-negative pattern) with the L3 input pattern described by Kaneko and co-workers for rat corticospinal neurons (see above). Indeed, the YFP-positive neurons in this line share certain features of corticospinal neurons (Sugino et al., 2006; Miller et al., 2008).

One of these features is a lack of adaptation during repetitive firing induced by prolonged depolarizing current injections at the soma. A recent study has identified the mechanistic basis for this (Miller et al., 2008). Studying the same YFP-H line and also using retrograde labeling methods to identify pyramidal tract (PT) neurons, Miller and Nelson showed that YFP-positive/PT neurons in motor cortex (but not in adjacent somatosensory cortex) exhibit a distinct form of spike frequency acceleration, due to a dendrotoxin-sensitive slowly inactivating current $\left(I_{\mathrm{D}}\right)$ carried by voltage gated potassium channels with Kv1 subunits. Because other classes of cortical projection neurons also show distinct repetitive firing and intrinsic properties (Molnar and Cheung, 2006; Hattox and Nelson, 2007), an important area for future studies is to explore how the particular intrinsic properties of different classes of output neurons confer cortical circuits with dynamic functional properties involved in motor control.

Synaptic properties are also an integral aspect of cortical information processing, and at the microcircuit level, pair recording methods (multiple simultaneous whole cell recordings) are elucidating the particular properties and patterns of unitary synaptic connections of small groups 
of neurons within agranular cortex, especially in medial frontal/prefrontal areas. Distinct sub-networks of (unlabeled) L5 neurons have been found: one type, similar to sensory cortical sub-networks, involves accommodative-firing neurons interconnected by depressing synapses; another involves non-accommodating neurons interconnected by synaptically facilitating contacts (Wang et al., 2006). Synaptic augmentation is also more pronounced for medial prefrontal synapses compared to sensory cortex (Hempel et al., 2000; Wang et al., 2006). Thus, medial agranular cortex contains microcircuit specializations that could be involved in supporting the types of persistent activity proposed to underlie working memory. Other studies in medial agranular cortex have demonstrated highly specific connections among defined pyramidal neuron sub-classes (Morishima and Kawaguchi, 2006; Otsuka and Kawaguchi, 2008), and studies in sensory cortex have identified highly specific microcircuits for unlabeled (Song et al., 2005; Yoshimura et al., 2005; Kampa et al., 2006) and retrogradely labeled pyramidal neurons (Brown and Hestrin, 2009). Further such studies of unitary connection properties of identified projection neurons in motorfrontal cortex (e.g. corticospinal, corticostriatal) are needed to address the question, "who talks to whom, and how?"

\section{PROSPECTS}

The growing toolbox of optical, electrophysiological, molecular, genetic, anatomical, and computational methods for cortical circuit analysis (Heintz, 2004; Lein et al., 2007; Luo et al., 2008;
Ng et al., 2009) presents many possibilities for dissecting the synaptic circuit organization of motor-frontal areas, despite the lack of traditional guideposts and fiduciary references at the level of in vitro cytoarchitectonics and in vivo receptive field properties. An important general area of research will be to determine the local circuits of major classes of projection neurons. For example, in motor-frontal areas the input circuits of corticospinal and corticostriatal neurons - cortical components of the 'pyramidal' and 'extrapyramidal' motor systems - can be determined by combining labeling and circuit mapping methods. Experiments of this type will allow linking of the local and long-range circuit organization. Channelrhodopsin-2 based methods provide many new opportunities for in vitro circuit mapping at subcellular (i.e., dendritic sub-arbor) levels of resolution (Petreanu et al., 2007, 2009). Optogenetic tools for in vivo manipulation of circuit activity (Zhang et al., 2007) hold promise for revealing the functional roles in behaving animals of circuits that are well characterized at the cellular and synaptic levels. Finally, the availability of neurological mouse models makes it realistic to apply this ensemble of circuit analysis tools to identify circuit pathophysiological mechanisms and targets for interventions.

\section{ACKNOWLEDGMENTS}

Sources of support: Brain Research Foundation, Howard Hughes Medical Institute, International Rett Syndrome Foundation, National Institutes of Health (NINDS Grant NS061963), Simons Foundation, Whitehall Foundation.

\section{REFERENCES}

Arenkiel, B. R., Peca, J., Davison, I. G., Feliciano, C., Deisseroth, K., Augustine, G. J., Ehlers, M. D., and Feng, G. (2007). In vivo lightinduced activation of neural circuitry in transgenic mice expressing channelrhodopsin-2. Neuron 54, 205-218.

Ayling, O. G., Harrison, T. C., Boyd, J. D., Goroshkov, A., and Murphy, T. H. (2009). Automated light-based mapping of motor cortex by photoactivation of channelrhodopsin-2 transgenic mice. Nat. Methods 6, 219-224.

Binzegger, T., Douglas, R. J., and Martin, K. A. (2004). A quantitative map of the circuit of cat primary visual cortex. J. Neurosci. 24, 8441-8453.

Brecht, M., Krauss, A., Muhammad, S., Sinai-Esfahani, L., Bellanca, S., and Margrie, T.W. (2004). Organization of rat vibrissa motor cortex and adjacent areas according to cytoarchitectonics, microstimulation, and intracellular stimulation of identified cells. J. Comp. Neurol. 479, 360-373.

Brown, S. P., and Hestrin, S. (2009). Intracortical circuits of pyramidal neurons reflect their long-range axonal targets. Nature 457, 1133-1136.

Callaway, E. M., (1998). Local circuits in primary visual cortex of the macaque monkey. Annu. Rev. Neurosci. 21, 47-74.

Callaway, E. M., and Katz, L. C. (1993). Photostimulation using caged glutamate reveals functional circuitry in living brain slices. Proc. Natl. Acad. Sci. U.S.A. 90, 7661-7665.

Caviness, V. S., Jr (1975). Architectonic map of neocortex of the normal mouse. J. Comp. Neurol. 164, 247-263.

Cho, R. H., Segawa, S., Okamoto, K., Mizuno, A., and Kaneko, T. (2004). Intracellularly labeled pyramidal neurons in the cortical areas projecting to the spinal cord. II. Intra- and juxta-columnar projection of pyramidal neurons to corticospinal neurons. Neurosci. Res. 50, 395-410.

Douglas, R. J., and Martin, K. A. (2004). Neuronal circuits of the neocortex. Annu. Rev. Neurosci. 27, 419-451.

Feng, G., Mellor, R. H., Bernstein, M., Keller-Peck, C., Nguyen, Q. T., Wallace, M., Nerbonne, J. M., Lichtman, J. W., and Sanes, J. R. (2000). Imaging neuronal subsets in transgenic mice expressing multiple spectral variants of GFP. Neuron 28, 41-51.

Frost, S. B., Milliken, G. W., Plautz, E. J., Masterton, R. B., and Nudo, R. J. (2000). Somatosensory and motor representations in cerebral cortex of a primitive mammal (Monodelphis domestica): a window into the early evolution of sensorimotor cortex. J. Comp. Neurol. 421, 29-51.

Hattox, A. M., and Nelson, S. B. (2007) Layer $\mathrm{V}$ neurons in mouse cortex projecting to different targets have distinct physiological properties. J. Neurophysiol. 98, 3330-3340.

Heintz, N., (2004). Gene Expression Nervous System Atlas (GENSAT). Nat. Neurosci. 7, 483.

Hempel, C. M., Hartman, K. H., Wang, X. J., Turrigiano, G. G., and Nelson, S. B. (2000). Multiple forms of short-term plasticity at excitatory synapses in rat medial prefrontal cortex. J. Neurophysiol. 83, 3031-3041.

Jones, E. G., (1975). Lamination and differential distribution of thalamic afferents within the sensory-motor cortex of the squirrel monkey. J. Comp. Neurol. 160, 167-203.

Kampa, B. M., Letzkus, J. J., and Stuart, G. J. (2006). Cortical feed-forward networks for binding different streams of sensory information. Nat. Neurosci. 9, 1472-1473.

Kaneko, T., Caria, M.A., and Asanuma, H. (1994a).Information processing within 
the motor cortex. II. Intracortical connections between neurons receiving somatosensory cortical input and motor output neurons of the cortex. J. Comp. Neurol. 345, 172-184.

Kaneko, T., Caria, M.A., and Asanuma, H. (1994b). Information processing within the motor cortex. I. Responses of morphologically identified motor cortical cells to stimulation of the somatosensory cortex. J. Comp. Neurol. 345, 161-171.

Kaneko, T., Cho, R., Li, Y., Nomura, S., and Mizuno, N. (2000). Predominant information transfer from layer III pyramidal neurons to corticospinal neurons. J. Comp. Neurol. 423, 52-65.

Kaneko, T., and Fujiyama, F. (2002). Complementary distribution of vesicular glutamate transporters in the central nervous system. Neurosci. Res. 42, 243-250.

Keller, A., (1993). Intrinsic synaptic organization of the motor cortex. Cereb. Cortex 3, 430-441.

Kichula, E. A., and Huntley, G. W. (2008). Developmental and comparative aspects of posterior medial thalamocortical innervation of the barrel cortex in mice and rats. J. Comp. Neurol. 509, 239-258.

Kuramoto, E., Furuta, T., Nakamura, K. C., Unzai, T., Hioki, H., and Kaneko, T. (2009). Two types of thalamocortical projections from the motor thalamic nuclei of the rat: a single neurontracing study using viral vectors. Cereb. Cortex. 19, 2065-2077.

Lefort, S., Tomm, C., Floyd Sarria, J. C., and Petersen, C.C. (2009). The excitatory neuronal network of the $\mathrm{C} 2$ barrel column in mouse primary somatosensory cortex. Neuron 61, 301-316.

Lein, E. S., Hawrylycz, M. J., Ao, N., Ayres, M., Bensinger, A., Bernard, A., Boe, A. F., Boguski, M. S., Brockway, K. S., Byrnes, E. J., Chen. L., Chen, L., Chen, T. M., Chin, M. C., Chong, J., Crook, B. E., Czaplinska, A., Dang, C. N., Datta, S., Dee, N. R., Desaki, A. L., Desta, T., Diep, E., Dolbeare, T. A., Donelan, M. J., Dong, H. W., Dougherty, J. G., Duncan, B. J., Ebbert, A. J., Eichele, G., Estin, L. K., Faber, C., Facer, B. A., Fields, R., Fischer, S. R., Fliss, T. P., Frensley, C., Gates, S. N., Glattfelder, K. J., Halverson, K. R., Hart, M. R., Hohmann, J. G., Howell, M. P., Jeung, D. P., Johnson, R. A., Karr, P. T., Kawal, R., Kidney, J. M., Knapik, R. H., Kuan, C. L., Lake, J.H., Laramee, A. R., Larsen, K. D., Lau, C., Lemon, T. A., Liang, A. J., Liu, Y., Luong, L. T., Michaels, J., Morgan, J. J., Morgan, R. J., Mortrud, M. T., Mosqueda, N. F., Ng, L. L., Ng, R., Orta, G. J., Overly, C. C., Pak, T. H., Parry, S. E.,
Pathak, S. D., Pearson, O. C., Puchalski, R. B., Riley, Z. L., Rockett, H. R., Rowland, S. A., Royall, J. J., Ruiz, M. J., Sarno, N. R., Schaffnit, K., Shapovalova, N. V., Sivisay, T., Slaughterbeck, C. R., Smith, S. C., Smith, K. A., Smith, B. I., Sodt, A. J., Stewart, N N., Stumpf, K. R., Sunkin, S. M., Sutram, M., Tam, A., Teemer, C. D., Thaller, C., Thompson, C. L., Varnam, L. R., Visel, A., Whitlock, R. M., Wohnoutka, P. E., Wolkey, C. K., Wong, V. Y., Wood, M., Yaylaoglu, M. B., Young, R. C., Youngstrom, B. L., Yuan, X. F., Zhang, B., Zwingman, T. A., and Jones, A. R. (2007). Genome-wide atlas of gene expression in the adult mouse brain. Nature 445, 168-176.

Li, C. X., and Waters, R. S. (1991). Organization of the mouse motor cortex studied by retrograde tracing and intracortical microstimulation (ICMS) mapping. Can. J. Neurol. Sci. $18,28-38$.

Luo, L., Callaway, E. M., and Svoboda, K. (2008). Genetic dissection of neural circuits. Neuron 57, 634-660.

Markram, H. (2006). The blue brain project. Nat. Rev. Neurosci. 7, 153-160.

Miller, M. N., Okaty, B. W., and Nelson, S. B. (2008). Region-specific spike-frequency acceleration in layer 5 pyramidal neurons mediated by Kv1 subunits. J. Neurosci. 28, 13716-13726.

Molnar, Z., and Cheung, A. F. (2006). Towards the classification of subpopulations of layer $\mathrm{V}$ pyramidal projection neurons. Neurosci. Res. 55, 105-115.

Molyneaux, B. J., Arlotta, P., Menezes, J. R., and Macklis, J.D. (2007). Neuronal subtype specification in the cerebral cortex. Nat. Rev. Neurosci. 8, 427-437.

Morishima, M., and Kawaguchi, Y. (2006). Recurrent connection patterns of corticostriatal pyramidal cells in frontal cortex. J. Neurosci. 26, 4394-4405.

Ng, L., Bernard, A., Lau, C., Overly, C. C., Dong, H. W., Kuan, C., Pathak, S., Sunkin, S. M., Dang, C., Bohland, J. W., Bokil, H., Mitra, P. P., Puelles, L., Hohmann, J.,Anderson, D. J.,Lein, E. S., Jones, A. R., and Hawrylycz, M. (2009). An anatomic gene expression atlas of the adult mouse brain. Nat. Neurosci. 12, 356-362.

Otsuka, T., and Kawaguchi, Y. (2008). Firing-pattern-dependent specificity of cortical excitatory feedforward subnetworks. J. Neurosci. 28, 11186-11195.

Petreanu, L., Huber, D., Sobczyk, A., and Svoboda, K. (2007). Channelrhodopsin-2-assisted circuit mapping of long-range callosal projections. Nat. Neurosci. 10, 663-668.
Petreanu, L., Mao, T., Sternson, S. M., and Svoboda, K. (2009). The subcellular organization of neocortical excitatory connections. Nature 457, 1142-1145.

Rathelot, J. A., and Strick, P. L. (2006) Muscle representation in the macaque motor cortex: an anatomical perspective. Proc. Natl. Acad. Sci. U.S.A. 103 , 8257-8262.

Rathelot, J. A., and Strick, P. L. (2009) Subdivisions of primary motor cortex based on cortico-motoneuronal cells. Proc. Natl. Acad. Sci. U.S.A. 106, 918-923.

Schieber, M. H., (2001). Constraints on somatotopic organization in the primary motor cortex. J. Neurophysiol. 86, 2125-2143.

Schuz, A., and Palm, G. (1989). Density of neurons and synapses in the cerebral cortex of the mouse. J. Comp. Neurol. 286, 442-455.

Shipp, S., (2005). The importance of being agranular: a comparative account of visual and motor cortex. Philos. Trans. R. Soc. Lond., B, Biol. Sci. 360 797-814.

Song, S., Sjostrom, P. J., Reigl, M., Nelson, S., and Chklovskii, D. B. (2005). Highly nonrandom features of synaptic connectivity in local cortical circuits. PLoS Biol. 3, 1-13. doi: 10.1371/journal.pbio.0030068.

Staiger, J. F., Flagmeyer, I., Schubert, D. Zilles, K., Kotter, R., and Luhmann, H. J. (2004). Functional diversity of layer IV spiny neurons in rat somatosensory cortex: quantitative morphology of electrophysiologically characterized and biocytin labeled cells. Cereb. Cortex. 14, 690-701.

Stepanyants, A., Hirsch, J. A., Martinez, L. M., Kisvarday, Z. F., Ferecsko, A. S., and Chklovskii, D. B. (2008). Local potential connectivity in cat primary visual cortex. Cereb. Cortex 18, 13-28.

Strick, P. L., and Sterling, P. (1974) Synaptic termination of afferents from the ventrolateral nucleus of the thalamus in the cat motor cortex. A light and electron microscopy study. J. Comp. Neurol. 153, 77-106.

Sugino, K., Hempel, C. M., Miller, M. N., Hattox, A. M., Shapiro, P., Wu, C., Huang, Z. J., and Nelson, S. B. (2006). Molecular taxonomy of major neuronal classes in the adult mouse forebrain. Nat. Neurosci. 9, 99-107.

Thomson, A. M., and Lamy, C. (2007). Functional maps of neocortical local circuitry. Front. Neurosci. 1, 19-42. doi: 10.3389/neuro.01.1.1.002.2007

Wang, Y., Markram, H., Goodman, P. H., Berger, T. K., Ma, J., and Goldman-Rakic, P. S. (2006). Heterogeneity in the pyramidal network of the medial prefrontal cortex. Nat. Neurosci. 9, 534-542.
Weiler, N., Wood, L., Yu, J., Solla, S. A., and Shepherd, G. M. (2008). Top-down laminar organization of the excitatory network in motor cortex. Nat. Neurosci. 11, 360-366.

Wise, S. P., (2008). Forward frontal fields: phylogeny and fundamental function. Trends Neurosci. 31, 599-608.

Wise, S. P., and Donoghue, J. P. (1986). Motor cortex of rodents. In Cerebral Cortex. Sensory-Motor Areas and Aspects of Cortical Connectivity, E. G. Jones and A. Peters, eds (New York, Plenum), pp. 243-270.

Wong, P., and Kaas, J. H. (2008). Architectonic subdivisions of neocortex in the gray squirrel (Sciurus carolinensis). Anat. Rec. (Hoboken) 291, 1301-1333.

Wong, P., and Kaas, J. H. (2009). Architectonic subdivisions of neocortex in the tree shrew (Tupaia belangeri) Anat. Rec. (Hoboken) 292, 994-1027.

Wood, L., Gray, N. W., Zhao, Z., Greenberg, M. E., and Shepherd, G. M. G. (2009). Synaptic circuit abnormalities of motor-frontal layer $2 / 3$ pyramidal neurons in an RNA interference model of methyl-CpG-binding protein 2 deficiency. J. Neurosci. (in press).

Yoshimura, Y., Dantzker, J. L., and Callaway, E. M. (2005). Excitatory cortical neurons form fine-scale functional networks. Nature 433, 868-873.

Yu, J., Anderson, C. T., Kiritani, T., Sheets, P. L., Wokosin, D. L., Wood, L., and Shepherd, G. M. (2008). Localcircuit phenotypes of layer 5 neurons in motor-frontal cortex of YFP-H mice. Front. Neural Circuits 2, 6. doi: 10.3389/neuro.04.006.2008

Zhang, F., Wang, L. P., Brauner, M., Liewald, J. F., Kay, K., Watzke, N., Wood, P. G., Bamberg, E., Nagel, G., Gottschalk, A., and Deisseroth, K. (2007). Multimodal fast optical interrogation of neural circuitry. Nature 446, 633-639.

Conflict of Interest Statement: The author declares that the research was conducted in the absence of any commercial or financial relationships that could be construed as a potential conflict of interest.

Received: 09 July 2009; paper pending published: 27 July 2009; accepted: 29 July 2009; published: 15 December 2009. Citation: Front. Neurosci. (2009) 3, 3: 337 343. doi: 10.3389/neuro.01.030.2009

Copyright (c) 2009 Shepherd. This is an open-access article subject to an exclusive license agreement between the authors and the Frontiers Research Foundation, which permits unrestricted use, distribution, and reproduction in any medium, provided the original authors and source are credited. 